\title{
The Effect of Different Rollover Conditions of the Vibrator on Human Injury
}

\author{
Qin $\mathrm{Li}^{1}$, Hang Liu ${ }^{*}, 1$, Zhiqiang Huang ${ }^{1}$, Yaping Ding ${ }^{1}$ and Xiaoping $\mathrm{Du}^{2}$ \\ ${ }^{1}$ School of Mechatronic Engineering, Southwest Petroleum University, Chengdu, 610500, China \\ ${ }^{2}$ Department of Mechanical and Aerospace Engineering, Missouri University of Science and Technology, Rolla, MO \\ 65409, USA
}

\begin{abstract}
Vibrator, as a crucial vehicle of oil and gas exploration, is challenged by the complex terrains. The probability of rollover accident is therefore high in bumpy terrain in which the drivers' life is seriously threatened. Finite element numerical analysis was used to study the injury of the driver's head, neck and chest in the rollover accidents of domestic KZ-28 type vibrator on different conditions. The injuries of three parts were evaluated based on the human injury criteria. Driver's safety on different rollover conditions was comparatively analyzed. The results indicated that the injury degree of human head caused by vibrator rollover accident is at a low level. In comparison with head, the human neck is more likely to be injured than head and chest. In three different rollover accidents, the injury degree of drivers on the rollover condition of the vibrator colliding with slope multiply is most serious. Besides, the results demonstrated that the safety of driver can be enhanced by the rollover protective structures of KZ-28 type vibrator. This structure requires to be improved in energy absorption and isolation buffer. In addition, the safety belt and collision angle between the cab and the ground are also significantly associated with the injury degree. This research is of guiding significance to vibrator driver for taking safety protection measures.
\end{abstract}

Keywords: Driver, human injury, rollover conditions, vibrator.

\section{INTRODUCTION}

Due to the shortage of oil and gas resources in China, their exploration and development need to be enhanced [1]. Vibrator, as an important vehicle of domestic oil and gas exploration, has increasingly extended the scope of oil and gas exploration geography and it involves the exploration of more serious environment places such as gobi, desert and piedmont belt. It is the best way to meet the domestic demand of oil and gas resources [2]. However, in the bumpy terrain, the vibrator operations risk increases, and the possibility of happening rollover accident rises significantly. Owing to vibrator is heavy equipment, the vibrator drivers' life suffer serious risks in the case of occurring rollover accidents [3]. The data based on the Census of Fatal Occupational Injuries (CFOI) released by a United States Bureau of Labor Statistics database during 1992 to1999 show that there are 54 deaths resulting from trenching and mining for all industries annually. Previous study found that there are 70 work zone deaths per year averagely, among which, 66 deaths are caused by vehicles or heavy equipment in work zones [4].

The research of vehicle rollover accident world widely mainly focuses on small cars, buses, agricultural vehicles, engineering vehicles (such as loaders, and excavators) [5].
M.D. Freeman et al. [6] considered that serious head and neck injuries are a common finding in fatalities associating with rollover crashes, and the relationship between a serious head and neck injury in an occupant. A specified degree of roof deformation at the occupant's seating position was found by establishing a predictive model. Chris Lee et al. [7] analyzed driver's injury severity in single- and two-vehicle crashes and compared the effects of explanatory variables among various types of crashes. This study identified factors affecting injury severity and their effects on severity levels according to 5-year's crash records for provincial highways in Ontario, Canada. Ximiao Jiang et al. [8] researched the effects of curbed outside shoulders on traffic-related injury severity. In this study, a zero-inflated ordered probity (ZIOP) model was employed to evaluate the influences of curbed outside shoulders. Yong Han Ju et al. [9] established multiple-dimensional injury variables to find the relationship between the categorical injury phenomena and the various traffic accident condition factors. David M. Neyens et al. [10] examined the factors which influenced those drivers experiencing or sustaining a traumatic brain injury (TBI); while other crashes involve drivers that had already experienced a TBI. Pontus Albertsson et al. [11] studied the effect of the different belt systems on the decrease of occupant's injuries in rollover coach crashes by analyzing 128 injured persons in rollover accident to represent the most common serious crash scenario for serious injury. They concentrated on the detection of the injury mechanism to avoid the reported injuries. The best belt scheme for occupants was obtained by Pontus Albertsson work. Melvin L. Myers et al. [12] compared the severity of fatal and 
nonfatal injuries between a $90^{\circ}$ and continuous roll for tractors with rollover protective structures (ROPS) and without a ROPS (non-ROPS). Melvin L. Myers work indicated that a ROPS was more effective of stopping an overturn at $90^{\circ}$ than that of no ROPS, with an associated reduction in the severity of injury in the event of a tractor overturn. Lori L. Travis et al. [13] analyzed the mortality of motorists after severe injury arising from traffic crashes in rural areas and obtained the factors of increasing the probability of severe injury. Chao Chen et al. [14] used a finite element method to verify the safety of the loader ROPS and indicated that the ROPS met the ISO 3471(1994) [15] standard, however fail to protect the operator from injury. Carol Conroy et al. [16] determined occupant, vehicle and crash characteristics which could predict serious injury during rollover crashes. Intrusion at the occupant's position, the vehicle interior side and roof, as sources of injury and improper safety belt use may lead to a serious injury.

However, the influence of the vibrator rollover accident on the driver injury has been rarely researched. Many researchers only studied a rollover condition for a certain vehicle type or the injury of a body part and did not taken the injuries of multiple body parts in different rollover conditions into account. To obtain the results of vibrator rollover accident to driver injury and provide the supports to vibrator driver for taking safety protection measures to reduce injury in rollover accident, this paper only investigated the rollover accident of the vibrator for the first time but also studied the driver's injury on different rollover conditions. It is necessary to study the domestic main vibrator type (KZ-28 type vibrator) affecting the driver's security when happening rollover accident. Besides, the indexes of three mostly vulnerable fatal parts (head, chest and neck) of the vibrator require to be analyzed to determine whether they meet the requirements of the safety evaluation criteria of human injury on different rollover conditions. Finite element numerical simulation method was adopted in this paper. LS-DYNA software was used to simulate the rollover process of vibrator. By analyzing results of injury of head, chest and neck on different rollover conditions, the authors put forwarded the suggestions of increasing safety for the vibrator driver in the case of driving.

\section{HUMAN INJURY CRITERIA}

At present, there have been no human injury criteria for the vibrator driver when occurring rollover accident. But global research into human injury criteria for the small car crashing has been mature [17]. So the human injury criteria of car crash test were used as reference standard for injury of the vibrator driver when occurring rollover accident. The criteria of human injury evaluation indexes are mainly proposed based on European New Car Assessment Program (NCAP) and Federal Motor Vehicle Safety Standard (FMVSS) [18]. The head, chest and neck are the most fatal parts on human body [19], so their injury degrees were mainly focused. Combining the criteria values of abovementioned three parts based on abbreviated injury scale (AIS), the severity of driver's injury can be predicted.

\subsection{Abbreviated Injury Scale}

"AIS" has been released by the American Association of Automobile Medicine (AAAM) [20] in 1976 for rating standards of human injury. It has been divided into six grades and each grade rule for the severity of human injury is shown in Table 1 [21].

Table 1. Abbreviated injury scale (AIS).

\begin{tabular}{|c|c|c|}
\hline AIS & Severity & Mortality/\% \\
\hline \hline 1 & Minor & 0.6 \\
\hline 2 & Moderate & 3.2 \\
\hline 3 & Serious & 9.3 \\
\hline 4 & Severe & 28.3 \\
\hline 5 & Life threatening & 78.4 \\
\hline 6 & Maximum & 100 \\
\hline
\end{tabular}

\subsection{Head Injury Criteria}

At present, the formula $\mathrm{HIC}_{36}$ calculated using Eq. (1), is mainly adopted to evaluate head injury. And $\mathrm{HIC}_{36}$ was released by the National Highway Traffic Safety Administration (NHTSA) in 1986 [22].

$$
\mathrm{HIC}_{36}=\max \left[\frac{1}{t_{2}-t_{1}} \int_{t_{1}}^{t_{2}} a(t) d t\right]^{2.5}\left(t_{2}-t_{1}\right)
$$

where $a(t)$ is resultant translational acceleration at the head center of gravity and $\left(t_{2}-t_{1}\right)=\mathrm{T}=36 \mathrm{~ms}$ (determining the maximal value). $\mathrm{HIC}_{36}$ is less than 1000 .

The values calculated by $\mathrm{HIC}_{36}$ are associated with AIS, and conclude the injury probability of head at all degrees. By calculation using Eq. (2) [23], we obtain

$$
p(\text { head injury })=\phi\left(\frac{\ln \left(H I C_{36}\right)-\mu}{\delta}\right)
$$

where $\phi$ refers to the cumulative normal distribution; $\mu$ is $6.96352 ; \sigma$ is 0.84664 which is representing AIS2 head injuries; $\mu=7.45231 ; \sigma=0.73998$ for denoting AIS3 head injuries; $\mu=7.65605$, and $\sigma=0.60580$ for presenting AIS4 head injuries.

\subsection{Neck Injury Criteria}

Neck injury evaluation formula $\mathrm{N}_{\mathrm{ij}}$ obtained by using Eq. (3), was released by NHTSA as early as in 1996 in a child injury report. The formula mainly considers the neck axial force and bending moment to the neck injury [24].

$N_{i j}=\frac{F_{z}}{F_{\text {int }}}+\frac{M_{y}}{M_{\text {int }}}$

where $\mathrm{FZ}$ is the axial force; $F_{\text {int }}$ is the critical intercept value of force for normalization, $F_{\text {int }}=4500 \mathrm{~N} ; \mathrm{M}_{\mathrm{y}}$ is the flexion/extension bending moment; $\mathrm{M}_{\mathrm{int}}$ denotes the critical intercept value for moment for normalization, Mint $=125$ $\mathrm{Nm} . \mathrm{N}_{\mathrm{ij}}$ is less than 1 . 
The relationship between neck injury evaluation formula $\mathrm{N}_{\mathrm{ij}}$ and the injury probability of each degree of neck is calculated as Eq. (4) [25].

$p($ neck injury $)=\frac{1}{1+e^{\left(\mu-\sigma N_{i j}\right)}}$

where $\mu=2.054$ and $\sigma=1.195$ for showing AIS2 neck injuries; $\mu=3.227$ and $\sigma=1.969$ for indicating AIS3 neck injuries; $\mu=2.693$ and $\sigma=1.195$ for AIS4 neck injuries; while $\mu=3.817$ and $\sigma=1.195$ for illustrating AIS5 neck injuries.

\subsection{Chest Injury Criteria}

Chest injury evaluation criteria CTI calculated by Eq.(5) comprehensively consider the maximum chest deformation and shear action causing the maximum acceleration value of spine in $3 \mathrm{~ms}$ [26].

$$
C T I=\frac{A_{\text {max }}}{A_{\text {int }}}+\frac{D_{\text {max }}}{D_{\text {int }}}
$$

where $A_{\max }$ and $D_{\max }$ are the maximum observed acceleration and deflection respectively; $A_{\text {int }}$ and $D_{\text {int }}$ are the corresponding maximum allowable intercept values; $\mathrm{A}_{\text {int }} \leq 90$ $\mathrm{g}$ and $\mathrm{D}_{\text {int }} \leq 103 \mathrm{~mm}$. CTI is less than 1 .

The probability of each degree of the chest injury is calculated using Eq. (6) [27].

$$
\begin{aligned}
& P_{f}^{i}=P_{1}^{i}+P_{2}^{i}+P_{3}^{i} \\
& P_{1}^{i}=\omega_{1 i} F_{1 i f}^{\prime} f_{1 i} \\
& P_{2}^{i}=V_{2 i} F_{2 i f}^{\prime} f_{2 i} \\
& P_{3}^{i}=\omega_{3 i} F_{3 i f}^{\prime} f_{3 i} \\
& F_{1 i f}^{\prime}, F_{2 i f}^{\prime}, F_{3 i f}^{\prime}
\end{aligned}
$$

where $\mu=4.847$ and $\sigma=6.036$ for showing AIS2 chest injuries; $\mu=8.224$ and $\sigma=7.125$ for presenting AIS3 chest injuries; $\mu=9.872$ and $\sigma=7.125$ for representing AIS 4 chest injuries; and $\mu=14.242$ and $\sigma=6.589$ for AIS5 chest injuries.

\section{SIMULATIONS MODELING OF VIBRATOR FOR ROLLOVER COLLISION}

\subsection{Finite Element Model of the Vibrator}

The vibrator in this study is the major domestic vibrator of type-KZ-28. According to the related data provided by manufacturer, the scale at 1:1 model for actual size of the vibrator was established. The important parts which have a great influence on the mass of KZ-28 type vibrator were considered. The counterweight block was set up to those which are difficult to be modeled. By removing the scattered parts on the vibrator, the whole vibrator model was constructed as shown in Fig. (1).

The model shown in Fig. (1) was divided into the finite element grids by Hypermesh software. According to the real material selection of KZ-28 type vibrator, the material of all parts was set to Q235A except for tire. The elastic-plastic change of materials in the collision process was simulated. The tire model was set on elastic material. In addition, the influence of internal inflation on tire was considered also.
All parts of material density were set to actual size to guarantee that mass of the simulation model is $30000 \mathrm{~kg}$ [28] and same as the actual mass of the vibrator.

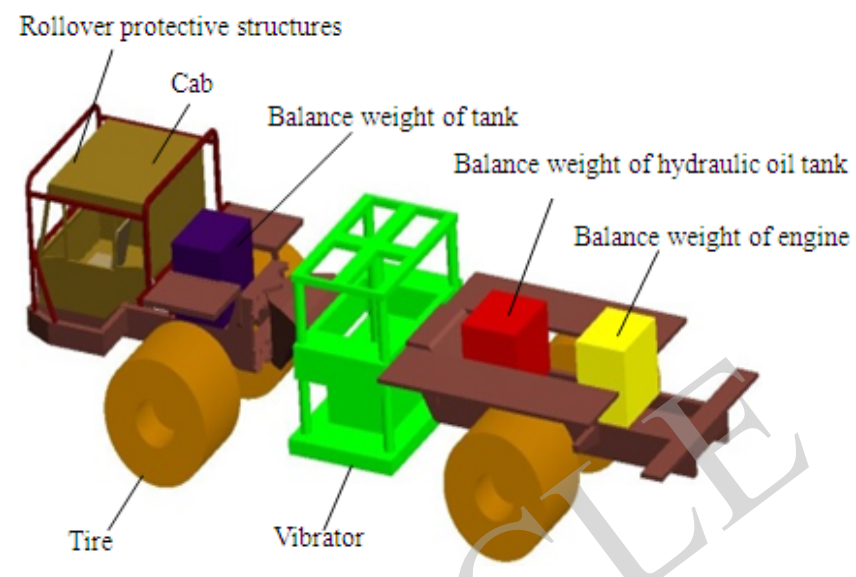

Fig. (1). KZ-28 type vibrator.

\subsection{Dummy Model}

A series of Hybrid III crash dummy models which were launched by General Motors in 1976 have been widely used in crash test and mainly divided into the Hybrid III $50^{\text {th }}$ male dummy, Hybrid III $5^{\text {th }}$ female dummy and Hybrid III $95^{\text {th }}$ false men [29]. In the study, the vibrator driver was considered as adult male with medium height, hence, the Hybrid III $50^{\text {th }}$ male dummy model was selected (Fig. 2) to represent the male with $175 \mathrm{~cm}$ in height and $78 \mathrm{~kg}$ in weight for medium height [30]. This was conforming to the actual conditions, and the dummy model was fitted with a threepoint belt (Fig. 3).

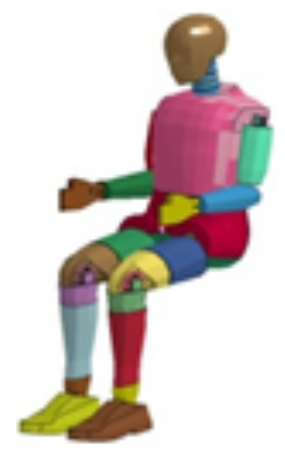

Fig. (2). Hybrid III $50^{\text {th }}$ male dummy.

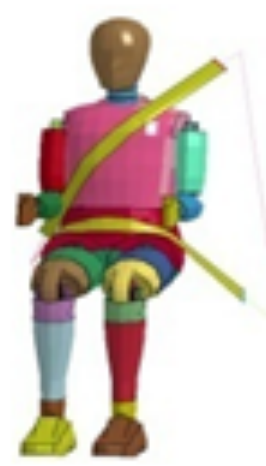

Fig. (3). Hybrid III $50^{\text {th }}$ male dummy with a three-point belt. 


\subsection{Boundary Conditions}

As shown in Fig. (4), the vibrator on a roll angle $\beta$ slope was in critical rollover state at this time. The line which contains the gravity point B of the vibrator and the point A on the outer edge of wheel had vertical relation with the ground. When the point $\mathrm{B}$ moved to the right of point $\mathrm{A}$, the line containing two points would no more had vertical relationship with the ground. So the vibrator would roll over by way of gravity. Therefore, the roll angle $\beta$ could be confirmed and the angle $\alpha$ is provided. The geometric relationship is calculated using Eq. (7).

$$
\alpha=\arctan \frac{h}{d}
$$

where $h$ is the center for gravity height of vibrator, $h=1830$ $\mathrm{mm} ; d$ is the half distance of the outer edge of wheel, $d=1827 \mathrm{~mm}$.

Calculating using equation 7, the angle $\alpha \approx 45^{\circ}$, hence the roll angle $\beta$ of the vibrator is $45^{\circ}$.

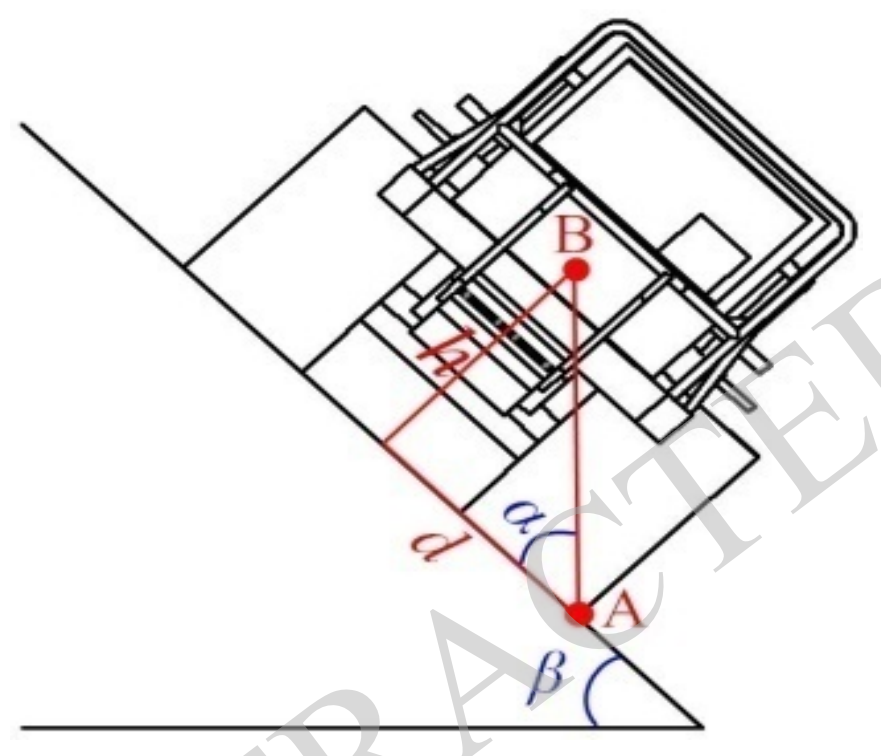

Fig. (4). Critical rollover state of vibrator.

Based on the above analysis, the vibrator would be likely to encounter a rollover accident when driving on a $45^{\circ}$ slope. In line with the critical boundary conditions, the whole rollover simulation model of the vibrator was established by using LS-DYNA software. The dummy model (Fig. 3) was introduced into the model (Fig. 5). According to the car crash safety regulations [31], the ground model was imposed by all displacement constraints and set to the rigid model. Hence, the boundary conditions of this simulation are set such that the vibrator rolls over on slope freely without initial velocity by gravity on rigid ground with a gradient of $45^{\circ}$.

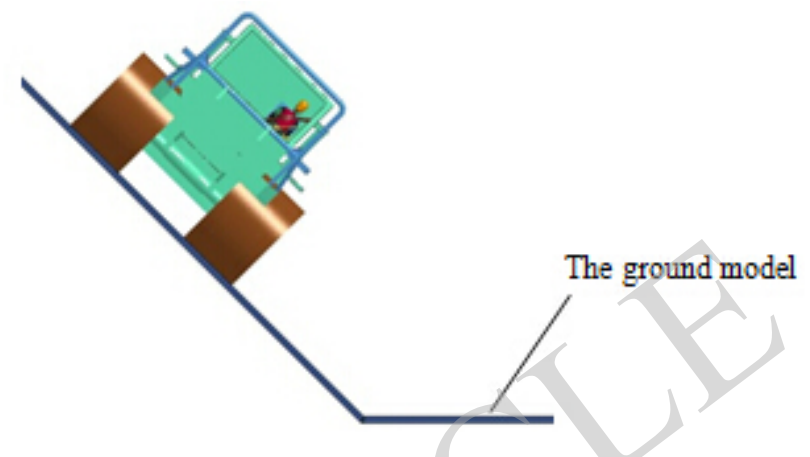

Fig. (5). The whole finite element simulation model.

\subsection{Rollover Conditions}

The $45^{\circ}$ slope using collision simulation environment model was calculated by relevant dimensions of KZ-28 type vibrator, however, the conditions of the vibrator rolling over on the slope are complicated. Three conditions of the vibrator rollover accidents can be roughly divided according to the slope position of the vibrator. The conditions of multiple collisions, a collision, and zero collision on slope are classified. The position of the ground models was adjusted correspondingly according to the three conditions, which were for modeling the finite element simulation model to meet three conditions of collisions respectively, as shown in Fig. (6). The vibrator rollover accident almost occurs in the movement process, but its speed is slow in view of taking brake action when occurring rollover accident, hence, the vibrator speed was assumed to be zero at the instability moment of rolling over.

As shown in Fig. (6a), owing to such slope is too long, if the vibrator rolls over on such slope environment, multiple collisions will likely to be happened between the cab and slope. This means that a $360^{\circ}$ rolling appears on slope, and the vibrator collides with the ground consequently. Fig. (6a) shows that the model that the cab collides with slope twice and the ground once. The injury caused by multiple collisions to driver can be reflected through studying such a collision situation.

\begin{tabular}{|l|l|l|}
\hline $\begin{array}{l}\text { (a) The rollover condition of multiple collisions on } \\
\text { slope }\end{array}$ & (b) The rollover condition of a collision on slope & (c) The rollover condition of zero collision on slope \\
\hline & &
\end{tabular}

Fig. (6). Three different conditions of rollover accident. 
The model in Fig. (6b) shows that the cab only collides with slope once, then collides with the ground. If the vibrator was driving on slope and close to the ground, the cab would not collide with slope, and only collide with the ground, as shown in Fig. (6c).

\section{SIMULATION RESULTS}

\subsection{Head Injury Evaluation Index}

On the three different rollover conditions, the head acceleration curves for dummy are shown in Fig. (7). On the basis of the numerical analysis, the maximum values of dummy's head injury evaluation criteria $\mathrm{HIC}_{36}$ on the different rollover conditions can be obtained, and its starting and ending time of a $36 \mathrm{~ms}$ time in the whole simulation time are also achieved.

Table 2. Head injury evaluation index on the different rollover conditions.

\begin{tabular}{|c|c|c|}
\hline & $\mathrm{HIC}_{36}$ & $\begin{array}{c}\text { Starting and Ending } \\
\text { Time (ms) }\end{array}$ \\
\hline \hline Multiple collisions on slope & 501.4 & $1448 \sim 1484$ \\
\hline A collision on slope & 115.5 & $1448 \sim 1484$ \\
\hline Zero collision on slope & 201.8 & $1227 \sim 1263$ \\
\hline
\end{tabular}

As shown in Table 2, the value of dummy's head injury criteria $\mathrm{HIC}_{36}$ is the maximum when the vibrator collides with the slope for many times. The driver's head injury is vulnerable among the most serious injuries in such rollover condition and more serious in the case of colliding with the ground directly than that of a collision on slope. Nonetheless, the dummy's head injury criteria meet the requirements of safety regulations in each rollover condition.

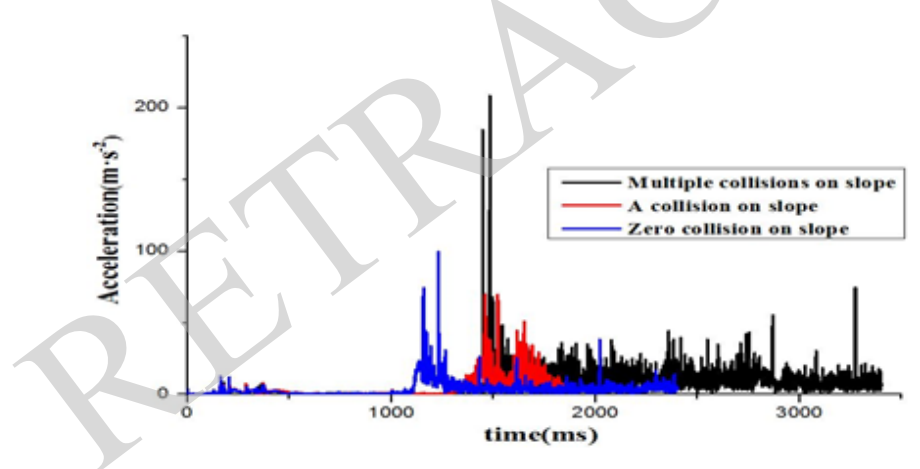

Fig. (7). Resultant acceleration curves for dummy's head within 36 ms.

\subsection{Neck Injury Evaluation Index}

\subsubsection{The Neck Axial Force}

The neck axial force is a key index for evaluating the neck injury. Fig. (8) shows that the value of neck axial force positively and negatively fluctuates with time in each rollover condition, so the neck in the axial direction was alternated by tension and pressure. The severity of neck injury was established by the maximum value of axial tension or pressure.
Table 3. Neck axial force on the different rollover conditions.

\begin{tabular}{|c|c|c|}
\hline & $\begin{array}{c}\text { The Maximum } \\
\text { Tension (N) }\end{array}$ & $\begin{array}{c}\text { The Maximum } \\
\text { Pressure (N) }\end{array}$ \\
\hline \hline Multiple collisions on slope & 4194 & 9604 \\
\hline A collision on slope & 3013 & 3147 \\
\hline Zero collision on slope & 2786 & 3278 \\
\hline
\end{tabular}

Table 3 presents the values of neck axial tension and pressure which are the maximum in the multiple rollover collisions on slope. They have exceeded the safety regulations for neck axial force, so that the severity of neck injury is the most serious. In three different rollover conditions, neck axial pressures are generally larger than tension; as a result, the neck is more vulnerable to suffer injury caused by axial pressure.

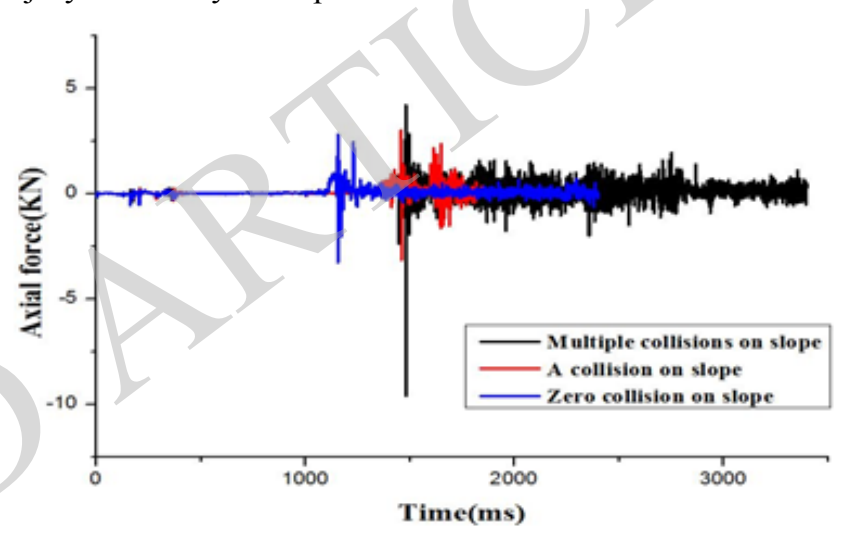

Fig. (8). Axial force curves for dummy's neck.

\subsubsection{The Neck Bending Moment}

Fig. (9) shows the bending moment of dummy's neck which is the maximum in the zero collision on slope. The value is $84.86 \mathrm{KN} \cdot \mathrm{mm}$. The maximum value of neck bending moment in the multiple collisions on slope is greater than that of a collision on slope: they are $45.15 \mathrm{KN} \cdot \mathrm{mm}$ and $26.66 \mathrm{KN} \cdot \mathrm{mm}$ respectively. So, in vibrator colliding with the ground directly after rolling, the driver's neck injury caused by bending moment was more serious. However, the values of neck bending moment met the requirements of safety regulations in three different rollover conditions.

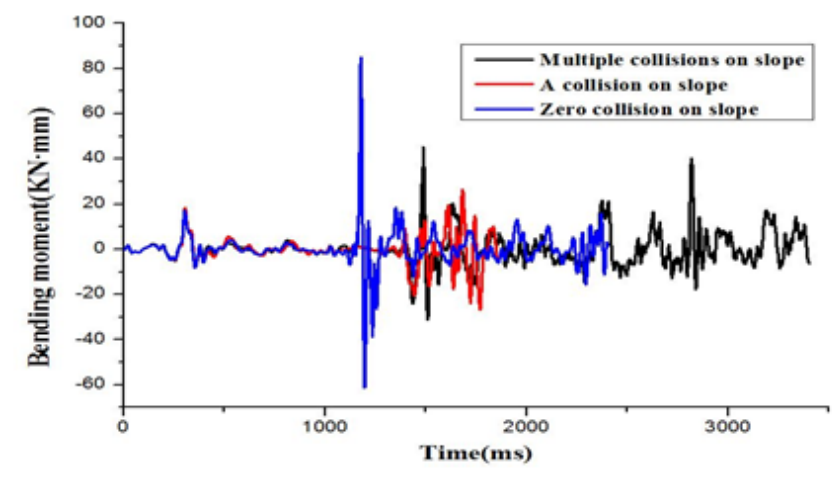

Fig. (9). Bending moment curves for dummy’s neck. 


\subsection{Chest Injury Evaluation Index}

\subsubsection{The Resultant Acceleration of the Spine}

The maximum resultant acceleration of the spine is an important reference for chest injury, which is caused by the shear effect during a period time of $3 \mathrm{~ms}$ within the rollover simulation time. As shown in Fig. (10), the resultant acceleration of spine led by multiple collisions on slope within $3 \mathrm{~ms}$ is maximized. Table 4 shows that concrete value of the resultant acceleration of spine in each rollover condition (g: acceleration of gravity).

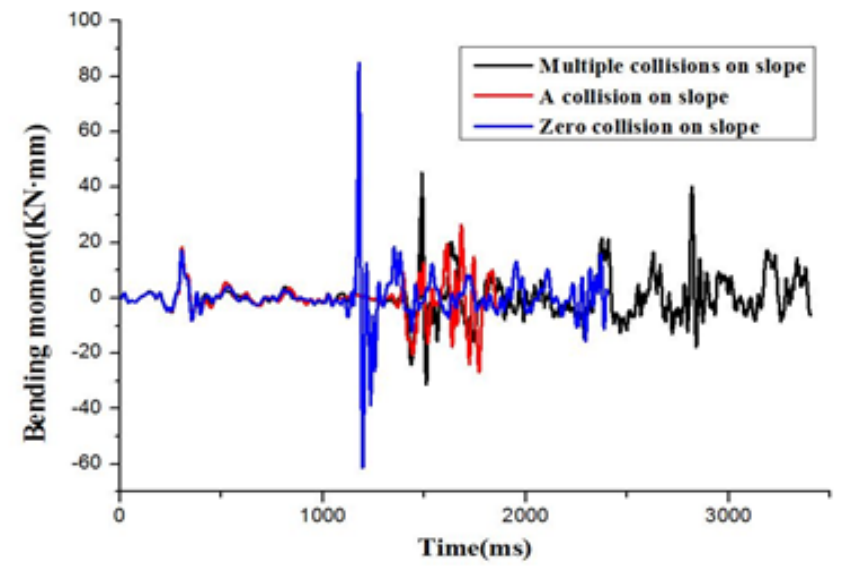

Fig. (10). Resultant acceleration curves for dummy's spine within 3 ms.

Table 4. Resultant acceleration of spine within $3 \mathrm{~ms}$ on the different rollover conditions.

\begin{tabular}{|c|c|c|}
\hline & $\begin{array}{c}\text { Acceleration } \\
\text { of } 3 \text { ms (g) }\end{array}$ & $\begin{array}{c}\text { Starting and } \\
\text { Ending Time (ms) }\end{array}$ \\
\hline \hline Multiple collisions on slope & 128.8 & $1479 \sim 1482$ \\
\hline A collision on slope & 47.8 & $1459 \sim 1462$ \\
\hline Zero collision on slope & 81.6 & $1154 \sim 1157$ \\
\hline
\end{tabular}

As shown in Table 4, in multiple collisions on slope, the resultant acceleration value of driver's spine is larger than that of the safety regulations. But other conditions are security.

\subsubsection{Chest Deflection}

The graph (Fig. 11) of chest deflection with time shows that the chest deflection of driver is maximized in rollover accident of multiple collisions on slope. The value reached $16.8 \mathrm{~mm}$. The chest deflection of driver when the vibrator collided with the ground directly in the case of rollover ranging between the rest of two conditions, and the value was $10.9 \mathrm{~mm}$. The chest deflection of driver in a collision on slope was minimized, and the value was $6.6 \mathrm{~mm}$. The chest deflection was far less than the value of safety regulations in three rollover conditions. So, the injury degree of the chest deflection caused by rollover accident was less.

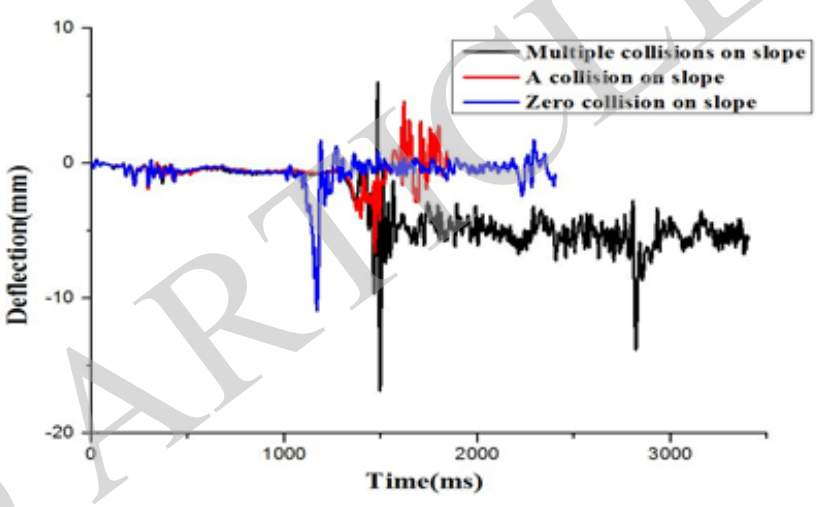

Fig. (11). Chest deflection curves for dummy.

\subsection{The Prediction of Driver Injury}

Based on the data of evaluation index for head, neck and chest injury, Equations (1), (3) and (5) were combined to evaluate the injury probability of AIS for each parts of driver; the results are shown in Table $\mathbf{5}$.

The data in Table $\mathbf{5}$ show that the probability of head injury is low on different rollover conditions. Therefore, head is not damaged seriously in the rollover accident due to the acceleration caused by collision.

In multiple collisions on slope, the probability of human injury was generally greater than that of the rest conditions.

Table 5. Predictive value of the probability of the risk of dummy injured in different rollover conditions.

\begin{tabular}{|c|c|c|c|c|c|c|}
\hline $2 x$ & & & Risk of AIS2 /\% & Risk of AIS3 /\% & Risk of AIS4 /\% & Risk of AIS5 /\% \\
\hline \multirow{3}{*}{ Multiple collisions on slope } & $\mathrm{HIC}_{36}$ & 501.4 & 11.9 & 4.8 & 0.9 & \\
\hline & $\mathrm{N}_{\mathrm{ij}}$ & 2.49 & 99.5 & 84.2 & 57.0 & 30.1 \\
\hline & CTI & 1.59 & 99.1 & 95.7 & 81.1 & 2.3 \\
\hline \multirow{3}{*}{ A collision on slope } & $\mathrm{HIC}_{36}$ & 115.5 & 0.5 & 0 & 0 & \\
\hline & $\mathrm{N}_{\mathrm{ij}}$ & 0.91 & 27.6 & 19.2 & 16.7 & 6.1 \\
\hline & CTI & 0.59 & 21.7 & 1.8 & 0.3 & 0 \\
\hline \multirow{3}{*}{ Zero collision on slope } & $\mathrm{HIC}_{36}$ & 201.8 & 2.6 & 0 & 0 & \\
\hline & $\mathrm{N}_{\mathrm{ij}}$ & 1.41 & 40.9 & 38.9 & 26.7 & 10.6 \\
\hline & CTI & 1.02 & 78.7 & 27.8 & 6.9 & 0 \\
\hline
\end{tabular}


Neck and chest of driver were likely to suffer more serious damage. Especially the chest and its probability encountering severe injury increased to $81.1 \%$. However, in the collision on slope, the neck was the most vulnerable to injury. For multiple and zero collision on slope, the values of CTI and $\mathrm{N}_{\mathrm{ij}}$ were greater than 1 , failing to meet the requirements of safety regulations.

(a)

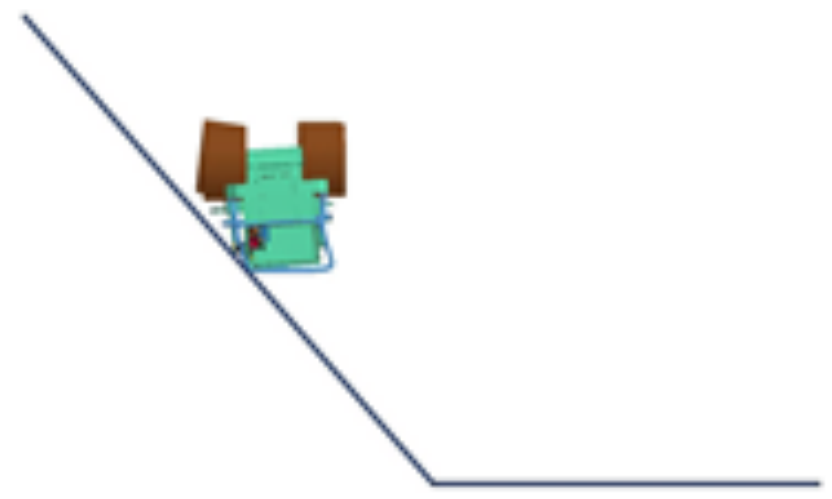

(b)

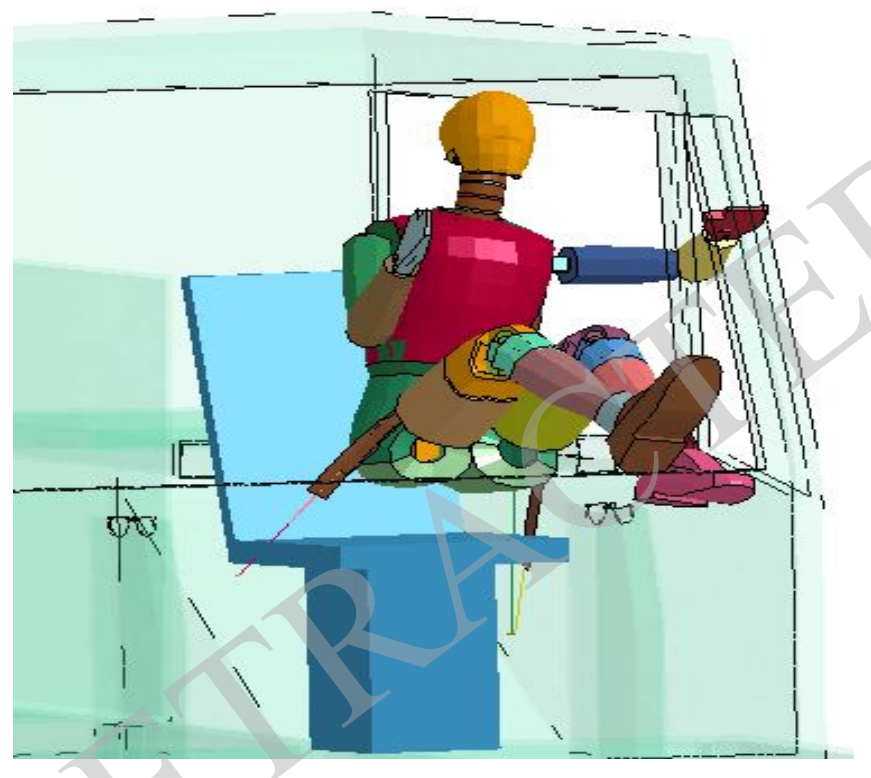

Fig. (12). Postures of the vibrator (a) and dummy (b) when colliding with the slope firstly.

\section{DISCUSSIONS}

\subsection{Rollover Condition of Multiple Collisions on Slope}

Several collisions tend to be caused when vibrator rolls over on a long slope. Firstly, the first collision happened on slope (Fig. 12a), and dummy model left the seat at the collision moment. Owing to the upper part for head space was small, the head of dummy model was likely to hit the cab interior, and the arm was put outside of the window (Fig. 12b). With continued tipping, the secondary collision occurred between the other side of rollover protective structures and slope (Fig. 13a). Since the activity space for the dummy was limited in the cab by the three-point belt, all body parts were set within security activities scope except left arm which was out of the window (Fig. 13b).
After rolling $360^{\circ}$ on slope, the vibrator continued rolling over forward due to the effect of inertia. Then the vehicle collided with the ground (Fig. 14a). At the third collision moment, the deflection of dummy's head was larger in comparison with previous two collisions. Part of its head was out of the window, and neck bent more due to seatbelt squeeze, and leg hit the cab interior (Fig. 14b).

(a)

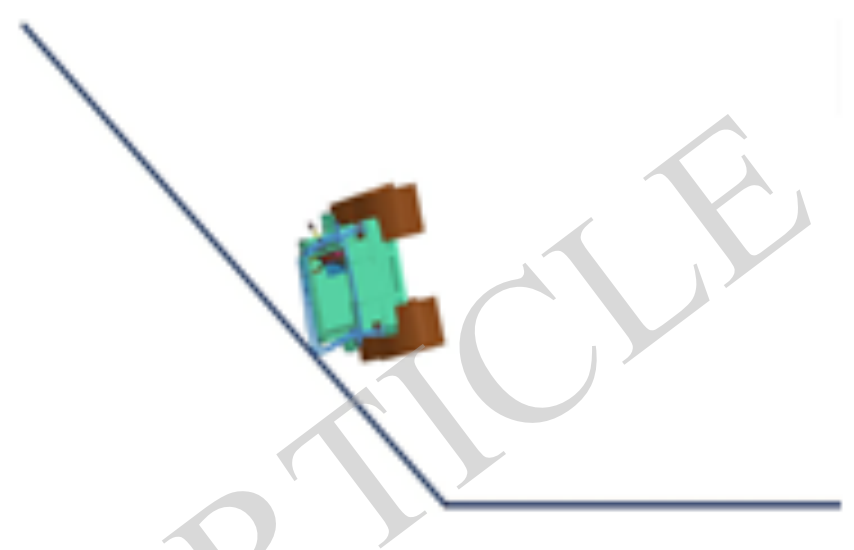

(b)

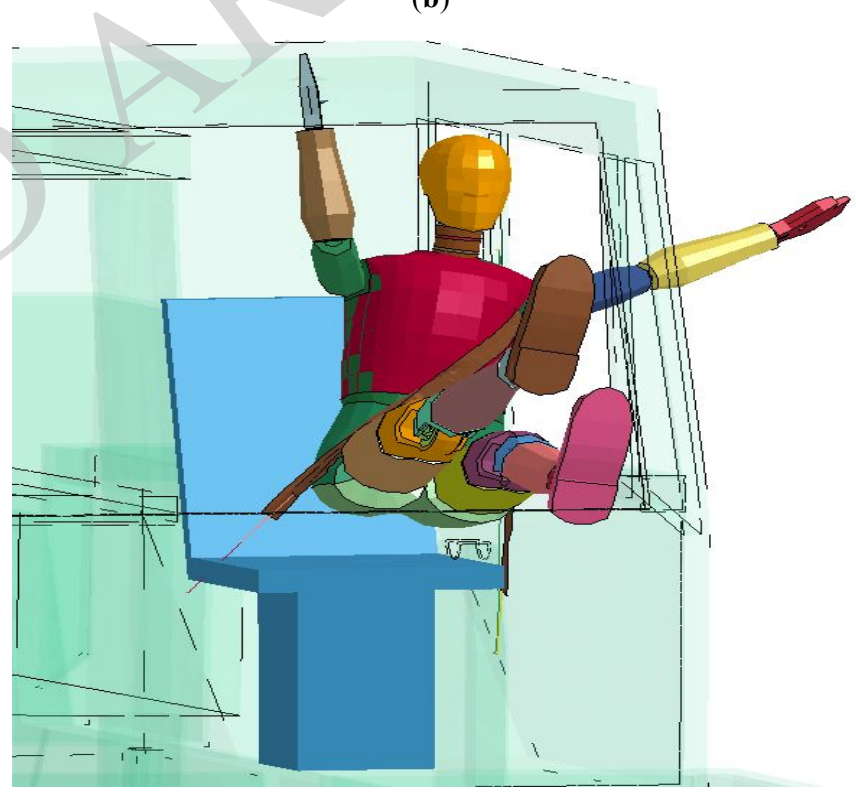

Fig. (13). The postures of the vibrator (a) and dummy (b) when colliding with the slope secondly.

\subsection{Rollover Condition of A Collisions on Slope}

When the vibrator rolled over on slope, the first collision occurred on slope (Fig. 15a). The plastic deformation of rollover protection structures and the cab were successively occurred in the collision. Meanwhile, dummy model left the seat because of the effect of inertia. Strong collision between dummy's head and the cab interior was prevented under the protection of three-point belt. Although dummy's head was close to the cab, there was no contact being happened (Fig. 15b). The vibrator continued tipping to the ground by gravity, and then the secondary collision happened (Fig. 16a). Meanwhile, the severe plastic deformation occurred on one side of rollover protective Structures to absorb part of the collision 
energy and increase the collision buffer time, so the degree of concussion caused by the secondary collision to driver was reduced. Dummy model suffered the strong force at the secondary collision moment. Its posture had been greatly extended, and. Most part of head was put outside the window, and the shoulder belt had been out of control in protection. Besides, the dummy was limited in the cab by the waist belt, a more serious injury was avoided because of ejection through the window (Fig. 16b).

(a)

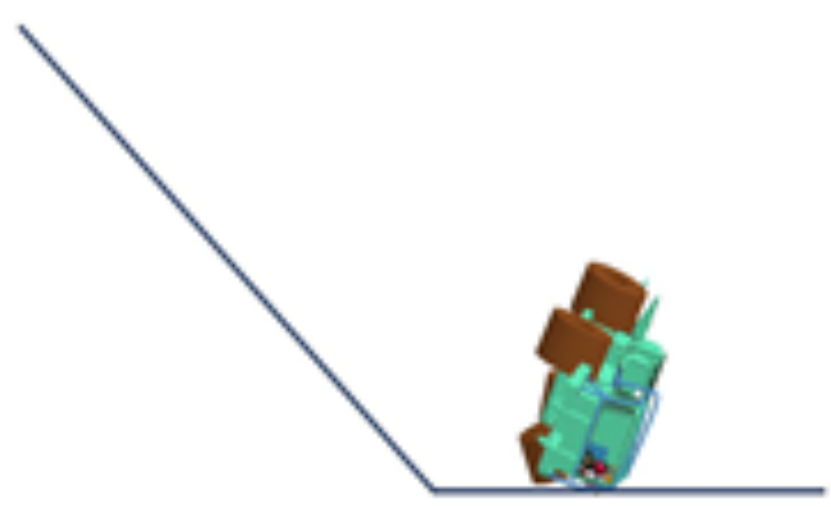

(b)

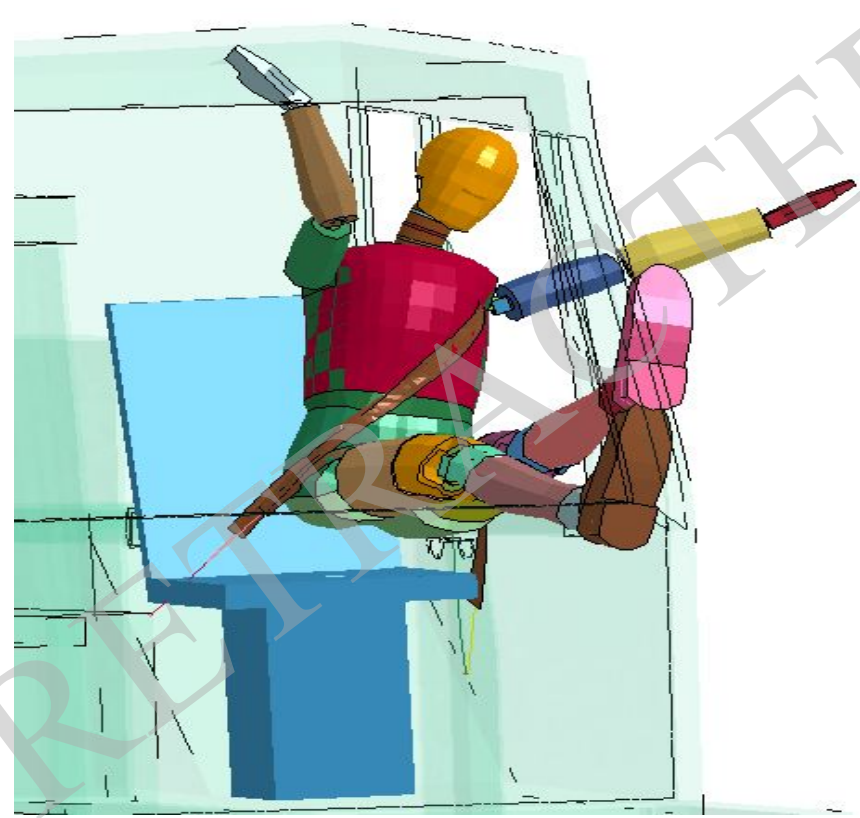

Fig. (14). Postures of the vibrator (a) and dummy (b) when colliding with the ground.

\subsection{Rollover Condition of Zero Collisions on Slope}

Rollover condition of zero collision on slope is the most common in the vibrator rollover. In actual driving operation, the probability that the vibrator drives on a long slope is minimal for the sake of security. The vibrator usually drives on the flat ground, if it encounters large obstructions or sloping wall, the rollover accidents will likely to occur,. Only one collision will happen in whole rollover process. The vibrator rolls over on the ground directly (Fig. 17a).
After rolling over on slope, the vibrator only collided with the ground. At the collision moment, the motion state of dummy is shown in Fig. (17b). Dummy's neck and waist were tightened by seatbelt to prevent dummy from being out of the window. But its head, left shoulder and left arm were outside the window, increasing the risk of injury.

(a)

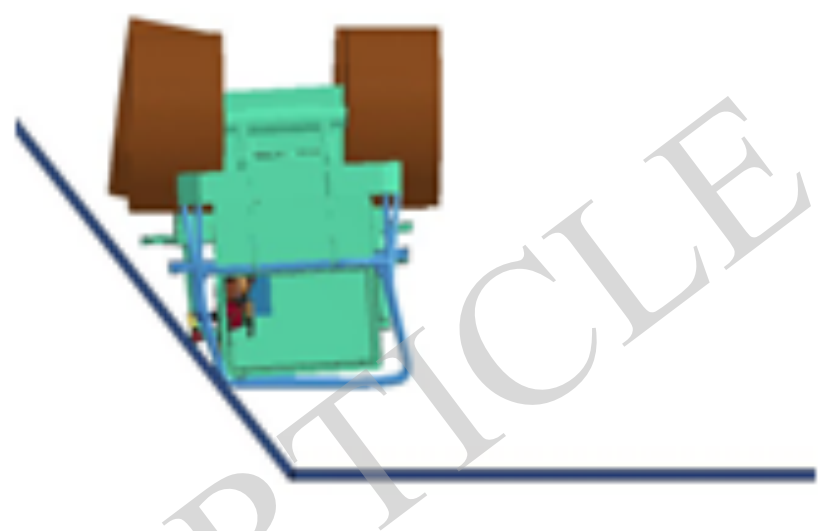

(b)

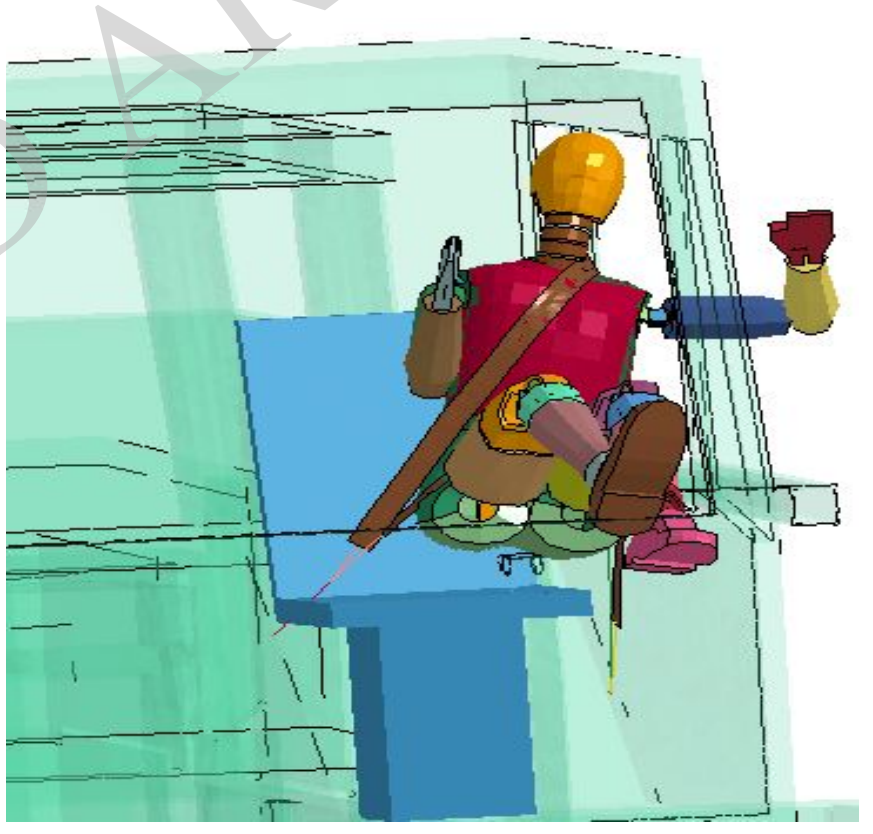

Fig. (15). Postures of the vibrator (a) and dummy (b) when colliding with the slope.

\subsection{Effect of Different Rollover Conditions}

In three different rollover conditions abovementioned, the head injury indexes were less, and met the requirements of safety regulations. The probability of different degrees of head injury was low; therefore, the driver's head was not apt to be damaged by the acceleration's mutation resulting from the vibrator rollover accident, so long as head did not hit other components. However, if the dummy's head had deflection and moved near the top edge of cab, it tended to hit the window and the top edge of cab, so the soft anticollision device requires to be installed near the window and 
(a)

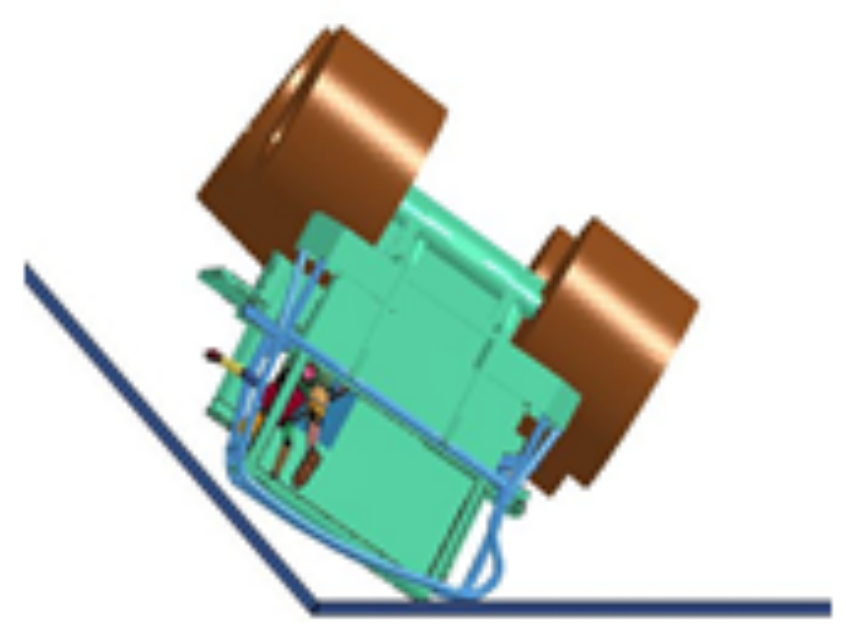

(b)

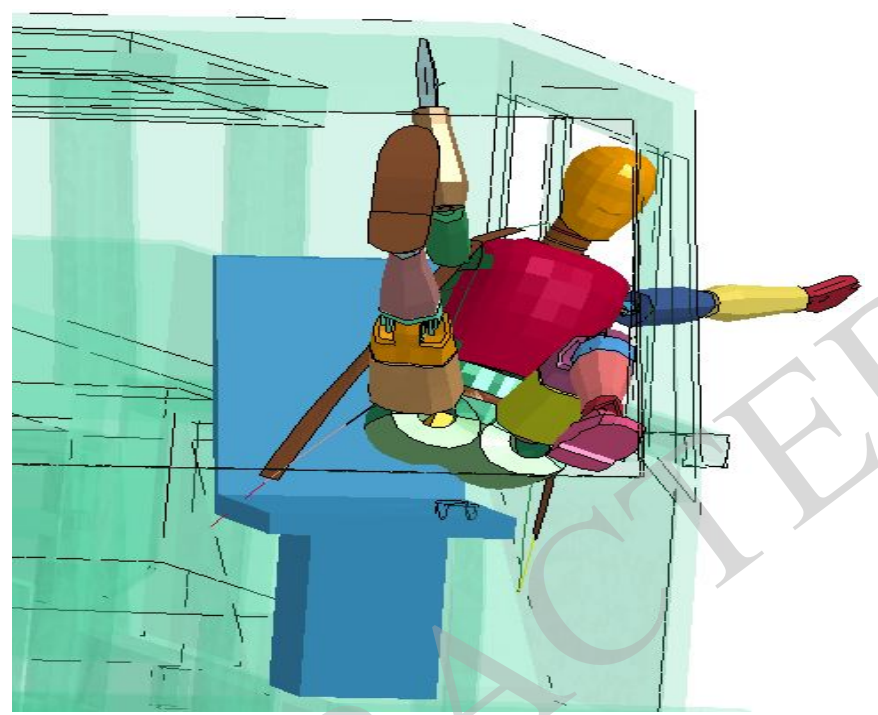

Fig. (16). Postures of the vibrator (a) and dummy (b) when colliding with the ground.

the top edge and top of cab to protect the head safety. In multiple collisions on slope, the values for the injury criteria of neck and chest for driver were maximum, and the injury probability of both parts in each injury degrees were higher than that of the rest conditions, so, the vibrator driving on a long slope can be avoided. In this way, the case of multiple collisions which cause continuous rolling to further increase the risk of driver injury can be avoided. In a collision on slope, the AIS probability of each part of human body was low due to the safety protection of rollover protective structures. The rollover protective structures play role of security protection through absorbing the collision kinetic energy by severe structural plastic deformation as well as its effect of isolation buffer. So, the rollover protective structures are an essential part for protecting the vibrator driver. To enhance the security of driver, the structure of rollover protective structures needs to be improved. Design criteria have to focus on the increase of energy absorption capacity and isolation buffer of the structure. In zero collision on slope, the angle between the side of cab and the ground (Fig. 17a) is smaller at the moment of colliding with the ground. The same situation is also found in multiple collisions on slope (Fig. 12a). However, the angle between the side of cab and the ground is larger in a collision on slope (Fig. 16a). But the risks of driver injuries were lower in all conditions. Therefore, it is believed that the angle between the side of cab and the ground is closely related with the risk of driver injury when colliding with the ground in addition to rollover protective structures and driving position. If the angle is smaller, the risk is higher.

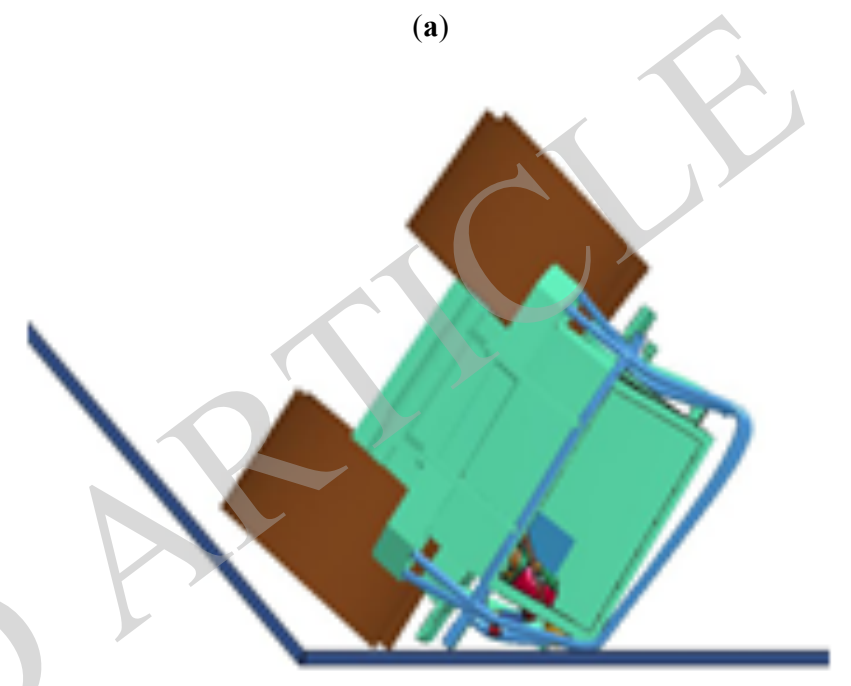

(b)

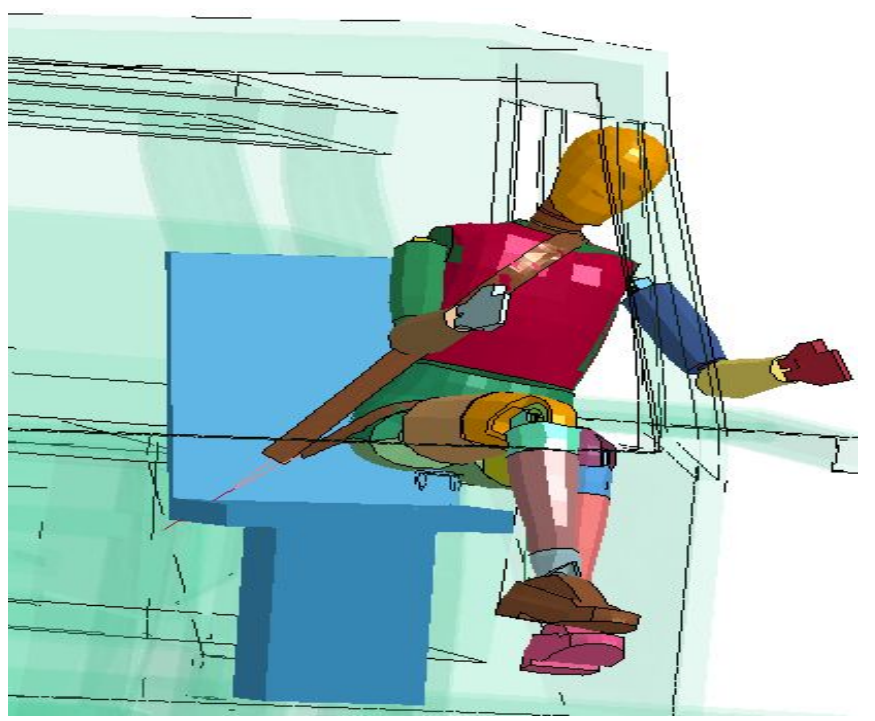

Fig. (17). Postures of the vibrator (a) and dummy (b) when colliding with the ground.

In the vibrator rollover accident, the human neck is more susceptible to suffer injury than head and chest. Therefore, the protection for driver's neck should be strengthened. In addition, the proper safety belt use has significant, positive impact on the injury degree, this is because the safety belt can prevent additional injuries by limiting the cab interior contacts and reducing the possibility of ejection. 


\section{CONCLUSION}

Based on human injury criteria and the AIS, This research evaluated the safety of the vibrator driver's head, neck and chest and predicated the injury probability of the AIS. Neck is the human part which is most likely to suffer from serious even severe injury in the rollover accident, followed by head and chest. In three rollover conditions, the multiple collisions on slope are the greatest threats to driver's safety owing to it presents a $360^{\circ}$ rolling to increase the possibility of serious injury. Therefore, the vibrator driving on a long slope should be cautioned and avoided. In addition, the driver's injury probability is influenced by the performance of rollover protective structures and the angle between the side of cab and the ground when colliding with the ground. Furthermore, the vibrator driver needs to fasten with a seat belt, so as to prevent from hitting the cab interior and being ejected. Further studies have to be made on the improvement of rollover protective structures and verification of the simulation results through field tests.

\section{CONFLICT OF INTEREST}

The authors confirm that this article content has no conflicts of interest.

\section{ACKNOWLEDGEMENTS}

Declared none.

\section{REFERENCES}

[1] A. Gao, and T. Nan, "Global oil and gas resource distribution and China's initiatives to secure overseas oil and gas supplies", SinoGlobal Energy, vol.16, no.9, pp. 15-16, 2011. (in Chinese)

[2] S. A. Holditch, "Unconventional oil and gas resource development - Let's do it right", Journal of Unconventional Oil and Gas Resources, vol. 1-2, pp. 2-8, 2013.

[3] K. M. Dobbertina, M. D. Freeman, W. E. Lambert, M. R. Lasarev, and S. S. Kohles, "The relationship between vehicle roof crush and head, neck and spine injury in rollover crashes", Accident Analysis and Prevention, vol.42, no.4, p. 47, 2013.

[4] M. McCann, "Heavy equipment and truck-related deaths on excavation work sites," Journal of Safety Research, vol.37, no.5, pp. 511-512, 2006.

[5] G. Maya, M. M. Boggess, and J. M. Duke, "Age related annual crash incidence rate ratios in professional drivers of heavy goods vehicles", Transportation Research Part A: Policy and Practice, vol. 65, pp. 2-3, 2014.

[6] M.D. Freeman, K. Dobbertin, S.S. Kohles, L. Uhrenholt and A. Eriksson, "Serious head and neck injury as a predictor of occupant position in fatal rollover crashes", Forensic Science International, vol.222, no.1-3, pp. 228-229, 2012.

[7] C. Lee and X. Li, "Analysis of injury severity of drivers involved in single- and two-vehicle crashes on highways in Ontario", Accident Analysis and Prevention, vol.71, pp. 286-295, 2014.

[8] X. Jiang, B. Huanga, R. L. Zaretzki, S. Richards, X. Yan, and H. Zhang, "Investigating the influence of curbs on single-vehicle crash injury severity utilizing zero-inflated ordered probit models", Accident Analysis and Prevention, vol.57, pp. 55-66, 2013.

[9] Y. H. Ju and S. Y. Sohn, "Quantification method analysis of the relationship between occupant injury and environmental factors in traffic accidents", Accident Analysis and Prevention, vol.43, no.1, pp. 342-343, 2011.
[10] D. M. Neyensa and N. B. Linda, "Crash risk factors related to individuals sustaining and drivers following traumatic brain injuries", Accident Analysis and Prevention, vol.49, pp. 266-267, 2012.

[11] P. Albertsson, T. Falkmer, A. Kirk, E. Mayrhofer and U.l.f. Bjornstig, "Case study: 128 injured in rollover coach crashes in Sweden-Injury outcome, mechanisms and possible effects of seat belts", Safety Science, vol.44, no.2, pp. 87-88, 2006

[12] M. L. Myers, H. P. Cole and S. C. Westneat, "Injury severity related to overturn characteristics of tractors", Journal of Safety Research, vol.40, no.2, p. 165, 2009.

[13] L. L. Travis, D. E. Clark, A. E. Haskins and J. A. Kilch, "Mortality in rural locations after severe injuries from motor vehicle crashes", Journal of Safety Research, vol.43, no.5-6, pp. 375-377, 2012.

[14] C. Chen, G. Wang, Y. Zhang, Y. Zhang, and J. Si, "Effect of lateral stiffness coefficient of loader ROPS on human injury in a lateral rollover incident”, Biosystems Engineering, vol.113, no.2, p. 207, 2012.

[15] ISO 3471, "Earth-moving machinery-Roll-over protective structures-Laboratory tests and performance requirements," 1994

[16] C. Conroy, D.B. Hoyt, A.B. Eastman, S. Erwin, S. Pacyna, T.L. Holbrook, T. Vaughan, M. Sise, F. Kennedy and T. Velky, "Rollover crashes: Predicting serious injury based on occupant, vehicle, and crash characteristics", Accident Analysis and Prevention, vol.38, no.5, pp. 835-842, 2006.

[17] J. Si, G. Wang, X. Wei and J. Wang, "Effect of rops stiffness, slope angle and seat-belt restraint on operator injury in rollover of engineering vehicle", Journal of Jilin University Engineering and Technology Edition, vol. 40, no. 6, pp. 1584-1585, 2010. (in Chinese)

[18] E. G. Takhounts, M. J. Craig, M. Kevin, and M.F. Joe, "Development of brain injury criteria", Stapp Car Crash Journal, vol.57, pp. 243-245, 2013.

[19] A. A. Weaver, K. A. Danelson, E. G. Armstrong, J. J. Hoth and J. D. Stitzel, "Investigation of pulmonary contusion extent and its correlation to crash, occupant, and injury characteristics in motor vehicle crashes," Accident Analysis and Prevention, vol.50, pp. 223-224, 2013.

[20] AAAM, Abbreviated injury scale, 2005 revision. Barrington, IL: Association for the Advancement of Automotive Medicine, 2005, pp. 847-846.

[21] C. Alen Cordero, G. Carbone, C. Marco, E. Javier and L. Jose, "Experimental tests in human-robot collision evaluation and characterization of a new safety index for robot operation", Mechanism and Machine Theory, vol.50, p. 187, 2014.

[22] S. M. Hsing, E. O. Stephen and T. H. Jang, "Designing against head injury while considering neck injury", Journal of Integrated Design \& Process Science, vol.11, no.1, pp. 41-59, 2007.

[23] H. Kimpara, and M. Iwamoto, "Mild traumatic brain injury predictors based on angular accelerations during impacts", Annals of Biomedical Engineering, vol.40, no.1, pp. 121-122, 2012.

[24] G.S. Nusholtz, L. Di Domenico, Y. Shi and P. Eagle, "Studies of neck injury criteria based on existing biomechanical test data", Accident Analysis and Prevention, vol.35, no.5, pp. 778-779, 2003.

[25] P. C. Ivancic, "Neck injury response to direct head impact," Accident Analysis and Prevention, vol.50, pp. 326-328, 2013.

[26] X. Lai, C. Ma, J. Hub, and Q. Zhou, "Impact direction effect on serious-to-fatal injuries among drivers in near-side collisions according to impact location: Focus on thoracic injuries", Accident Analysis and Prevention, vol.48, pp. 448-449, 2012.

[27] Y. Han, J. Yang, M. Koji and Y. Matsui, "A study on chest injury mechanism and the effectiveness of a head form impact test for pedestrian chest protection from vehicle collisions", Safety Science, vol.50, no.5, pp. 1307-1310, 2012.

[28] H. Yang and M. Tian, "Design and computation of brake system in KZ-28 type vibrator", Equipment for Geophysical Prospecting, vol.16, no.1, pp. 25-26, 2006. (in Chinese)

[29] D. C. Viano, C. S. Parenteau and R. Burnett, "Influence of standing or seated pelvis on dummy responses in rear impacts", Accident Analysis and Prevention, vol.45, no.2, pp. 423-424, 2012. 
[30] J. Hu, K. D. Klinich, M. P. Reed, M. Kokkolaras and J. D. Rupp, "Development and validation of a modified Hybrid-III six-year-old dummy model for simulating submarining in motor-vehicle crashes," Medical Engineering \& Physics, vol. 34, no. 5, p. 543, 2012.
[31] D. W. Harless and G. E. Hoffer, "Do laboratory frontal crash test programs predict driver fatality risk? Evidence from within vehicle line variation in test ratings," Accident Analysis and Prevention, vol.39, no.5, pp. 902-904, 2007.

Received: December 8, 2014

(C) Li et al.; Licensee Bentham Open.

This is an open access article licensed under the terms of the Creative Commons Attribution Non-Commercial License (http://creativecommons.org/licenses/by-nc/3.0/) which permits unrestricted, non-commercial use, distribution and reproduction in any medium, provided the work is properly cited. 